\title{
Induction of ovulation and natural oestrous cycling in the Stripe-faced Dunnart, Sminthopsis macroura
}

\author{
E Menkhorst, N Ezard and L Selwood \\ Department of Zoology, The University of Melbourne, Parkville, 3010 Victoria, Australia \\ Correspondence should be addressed to L Selwood; Email: I.selwood@zoology.unimelb.edu.au \\ E Menkhorst and N Ezard equally contributed to this work
}

\begin{abstract}
Induced ovulation allows reproduction by otherwise infertile females, and is ideal for the captive breeding of endangered species where the population is aged or breeding is unsuccessful. A predictable time of ovulation after induction has not yet been achieved in polyovular marsupials. Ovulation was induced in Sminthopsis macroura using an initial injection of 20 IU equine serum gonadotrophin (eSG; Day 0), followed on Day 4 by either 20 IU eSG $(n=25)$ or 0.5 mg porcine luteinizing hormone $(n=26)$. I.p. hormone injection was given in the morning or early evening, and reproductive status was established prior to induction. Five non-cyclic animals began to cycle naturally following induction and one gave birth to a litter. The time of ovulation after the 1 st injection $(7.8 \pm 0.9$ days) was significantly shorter $(P=0.000)$ and less variable than the previous study, mimicked the timing of natural cycling, and both natural and induced animals ovulated in the early morning. In vitro oocyte movement through the oviduct, observed for the first time in a marsupial, occurred in pulses. We estimated one group of oocytes could travel the length of the oviduct in $\mathbf{4 0} \mathbf{~ m i n}$, but it was probably around $\mathbf{4} \mathbf{~ h}$. The entire ovulation time (including multiple ovulations) was estimated at $7.5 \mathrm{~h}$. This study has achieved a predictable timing of ovulation after stimulation, and induced noncyclic animals to cycle naturally and give birth, providing a modified methodology for use in captive breeding programs of endangered dasyurid marsupial species with low fecundity.

Reproduction (2007) 133 495-502
\end{abstract}

\section{Introduction}

Manipulation of ovulation allows the captive breeding of both endangered and laboratory species to be optimised. It allows the use of infertile animals, whether seasonal or physiological, increasing the productivity of the colony and aiding the collection of reliably timed samples. In Australia, more than $30 \%$ (18 of 55 species) of all dasyurids (Menkhorst \& Knight 2004) are listed as threatened (Department of Environment and Heritage 2006, EPBC Act List of Threatened Fauna; Commonwealth of Australia, www.deh.gov.au), and a successful captive breeding program, including a reliable induced ovulation protocol, is essential.

Ovulation has been induced in all marsupial species studied, and although a behavioural oestrus is quite difficult to induce, it has been observed in Macropus eugenii, Monodelphis domestica, Sminthopsis crassicaudata (Hinds et al. 1996) and Sminthopsis macroura (Hickford et al. 2001). The current challenge for polyovular marsupials is obtaining a predictable timing of ovulation following induction.
Equine serum gonadotrophin (eSG), which functions with both follicle stimulating hormone $(\mathrm{FSH})$ and luteinizing hormone (LH)-like activity (Hinds et al. 1996), has been used to stimulate follicle development in many marsupial species. In Dunnarts (S. crassicaudata (Rodger et al. 1992) and S. macroura (Hickford et al. 2001)), a single dose induces ovulation, however, in $S$. macroura, negative side-effects were observed, including nausea and increased numbers of luteinized follicles (LF; Hickford et al. 2001). A measure of $0.087 \mathrm{IU} / \mathrm{g}$ eSG given as two doses, does not have these problems, but results in an unpredictable time of ovulation (3-16 days after initial injection), with only $41 \%$ of animals ovulating by Day 9 post-injection (Hickford et al. 2001). The range of ovulation times is not given for $S$. crassicaudata, in which $66 \%$ had ovulated by Day 6 post-injection (Rodger et al. 1992).

The time taken by oocytes for oviduct transit has not been experimentally confirmed in any marsupial species. Available data (Tyndale-Biscoe \& Renfree 1987, Selwood \& Woolley 1991, Breed \& Leigh 1992), and the onset of cleavage after uterine entry in all species 
(Tyndale-Biscoe \& Renfree 1987) suggests that it is probably $<24 \mathrm{~h}$ in marsupials, significantly shorter than the 3-4 days that oocytes and conceptuses remain in the eutherian oviduct (Harper 1988).

S. macroura is a polyoestrous, polyovular, seasonally breeding dasyurid marsupial (Woolley 1990). The oestrous cycle length is 23.25 days (Woolley 1990). Day 0 of the oestrous cycle is defined as the day before the first day of body weight rise, indicating the beginning of the follicular phase (Selwood \& Woolley 1991). Oestrus occurs after 3-4 days and spontaneous ovulation terminates the follicular phase after 6-7 days (Selwood \& Woolley 1991).

In order to get a more predictable response following induced ovulation, the timing of the two hormone injections was modified to more closely replicate the natural hormonal stimulus on the ovary. The time between the two injections was reduced from 5 days (Hickford et al. 2001) to 3.75 or 4 days, which is when oestrus begins, and both morning and evening injection times were tested. Porcine LH was used for the first time in a polyovular marsupial and we also present the first in vitro investigation of oviducal transit by oocytes in a marsupial.

\section{Materials and Methods}

\section{Animals}

A laboratory colony maintained at The University of Melbourne by LS, following Australian National Health and Medical Research Council Guidelines for the Care and Use of Animals for Scientific Purposes, provided the 92 S. macroura females used in this study.

Daily monitoring of urine and body weight as previously described in Hickford et al. (2001), identified oestrous cycles. The follicular phase is $6-7$ days long and is indicated by a steady rise in animal weight associated with increased cornified epithelial cell number in the urine. A weight drop associated with high levels of polymorphonuclear leucocytes in the urine sample indicates ovulation has occurred (Selwood \& Woolley 1991) and is deemed time 0 of gestation (Selwood \& Hickford 1999). Oviduct passage time is estimated as $8 \mathrm{~h}$ (Selwood \& Woolley 1991). The luteal phase, which is contained within the gestation phase, begins the following morning on Day 1 and is maintained until Day 9 of gestation (Selwood \& Woolley 1991). The gestation phase is only 10.7 days long (Selwood \& Woolley 1991), the shortest of any mammal. A sharp drop in body weight, accompanied by yellow crystals in urine, a clear secretion in the pouch, and pouch young if pregnant, ends the gestation phase. The time between the end of these changes in a non-pregnant cycle and the beginning of the next follicular phase is termed the intermediate phase.

Animals were grouped according to their reproductive phase at initial stimulation: non-cyclic, or the follicular, gestation and intermediate phase of the oestrous cycle. Stimulation during the middle of the gestation phase is generally unsuccessful, probably due to high ovarian progesterone levels (Hickford et al. 2001), so in this study stimulation only occurred early or late in the gestation phase, when corpora lutea (CL) influence was minimal.

\section{Treatments}

The day of the 1 st injection was designated as Day 0 and the female was monitored daily until killed between Days 6 and 15. A male was placed in with the female on Day 4, and if mating was not observed, a new male was introduced on Days 5 and 6. Naturally cycling females were killed between Days 6 and 8 of the oestrous cycle with Day 0 of the natural cycle being the day before the first day of weight rise. Five females identified as non-cyclic were induced to ovulate using both eSG/eSG $(n=2)$ and eSG/LH $(n=3)$, and then allowed to cycle naturally once $(n=3)$ or twice $(n=2)$, before they were killed between Days 6 and 8 of the subsequent natural oestrous cycle unless pouch young were born.

Previous induced ovulation protocols have calculated the hormonal dose based on animal weight. Here, we have attempted to simplify the procedure by giving a constant dose to all animals. An initial injection of $20 \mathrm{IU}$ eSG (Folligon, Allhank Trading Co., South Melbourne, Vic, Australia) was given in $100 \mu \mathrm{L}$ calcium- and magnesium-free PBS at either 10:00 or 18:00 h on Day 0 . A subsequent injection of either $20 \mathrm{IU}$ eSG or $0.5 \mathrm{mg}$ porcine LH, also in $100 \mu \mathrm{L}$ PBS (a gift from Bioniche Animal Health, Armidale, NSW, Australia), was given at 10:00 or 18:00 h on Day 4. The diluted hormone was hand-warmed before i.p. injection just above the pouch using a $1.0 \mathrm{~mL}$ sterile syringe with a 30 -gauge needle.

The interval between the $1 \mathrm{st}$ and 2 nd injection varied from 3.75 days (18:00 Day 0 to 10:00 Day 4 evening/morning (E/M)), to 4 days (10:00 Day 0 to 10:00 Day 4 - morning/morning (M/M); or 18:00 Day 0 to 18:00 Day 4 - evening/evening (E/E)).

\section{Analysis}

All experimentation began between 07:00 and 10:00 $\mathrm{h}$ to target ovulation. S. macroura is nocturnal, so it was assumed the ovulation time would be similar to other nocturnal animals, such as rats (Pederson 1951, Austin \& Braden 1954) and mice (Runner 1947). This assumption was supported by the fact that oviducal oocytes and conceptuses were most regularly found in the morning (Selwood \& Woolley 1991). Females were killed by inhalation of Halothane (Rhone Merieux, West Footscray, Vic, Australia) followed by cervical dislocation. The reproductive tract was removed and washed in warmed $\left(35^{\circ} \mathrm{C}\right)$ PBS. The ovary was examined under a dissecting microscope (Zeiss, North Ryde, NSW, Australia) to confirm the oestrous cycle stage and to identify the number, presence and size of Graafian follicles (GF) and 
CL. The GF were examined to identify LF or atretic follicles (AF). Ovaries from animals allowed to cycle naturally for one or two cycles after induction were examined for the number of corpora albicans (CA) present. CA can identify how many oocytes were ovulated in the previous cycle (Woolley 1990). The transparent oviducts were carefully examined under transmitted light to identify any oocytes. The uteri were slit medially and any contents were analysed using the criteria from Selwood \& McCallum (1987) to assess fertilization and normal development. The developmental stage of GF, CL and uterine contents were used to estimate the time of ovulation after the first injection, except in over-stimulated animals with AF and LF present.

\section{Time of oviducal transit}

Reproductive tracts found with oocytes in the oviduct, were placed whole into a sterile $35-\mathrm{mm}$ Petri dish (Greiner, Interpath Services, West Heidelberg, Vic, Australia) containing Hepes Buffered Dulbecco's Modified Eagles Medium (HDMEM, Sigma-Aldrich, Castle Hill, NSW, Australia) supplemented with $10 \%$ Foetal Calf Serum (Sigma-Aldrich) and held at $35^{\circ} \mathrm{C}$. Initial trials, in which the oviduct was straightened and affixed to wax, or in which the oviducts were held in continuous white light, resulted in the cessation of peristalsis within 10-15 min. Therefore, the oviduct was left attached to the ovary and uterus, and in between observations was covered by a box. The position of the oocytes in the oviduct was noted every 10 min for up to $1 \mathrm{~h}$, and after this, at intervals of $1 \mathrm{~h}$ or less. Brief observations ( $2 \mathrm{~min}$ ) of oocyte position were made under transmitted white light using a dissecting microscope with a heated stand. The oocytes were grouped according to the region of the oviduct that they were found: upper and lower ampulla, and upper and lower isthmus. Once the oviducts ceased peristalsis, or if the oocytes had not moved for more than $2 \mathrm{~h}$, the experiment ceased.

\section{Statistics}

The proportion of animals induced, identified by the presence of ovarian stimulatory products (GF or $\mathrm{CL}$ ), was calculated from all animals given the hormonal stimulation. The proportion of animals showing mating success, identified from observed behaviour and/or the presence of sperm in morning urine samples, was calculated as the proportion of induced animals that mated when paired with a male. The proportion of animals showing ovulation success was calculated as the proportion of animals examined after Day 7 that had ovulated. The proportion of animals showing fertilization success was calculated from animals that were found with zygotes that had been paired with a male. The proportion of animals that were stimulated, mated, ovulated and fertilized was compared with the reproductive phase of initial stimulation, and induction hormone and time of injection using a $\chi^{2}$-test. The number of $\mathrm{CL} / \mathrm{GF}, \mathrm{LF}, \mathrm{AF}$, ovulated oocytes and conceptuses were calculated as the mean \pm s.D. for each group and analyzed using one-way ANOVA followed by Bonferroni's post-hoc test to identify significant differences at $P<0.01$. The time of ovulation (pre- and post- the time of experimentation) was estimated from daily monitoring, ovarian appearance (GF and CL), oviducal appearance and (if present) conceptus development. To compare the time of ovulation after induction to the previous study, a one-sample $t$-test using the mean value from Hickford et al. (2001) as the test value was used, and an independent sample $t$-test compared the time of ovulation between induced and natural cycles. Two-way ANOVA compared the time of ovulation after initial injection for the two hormones given and the time of hormone injection. The level of significance, except for Bonferroni's post-hoc test, was $P \leq 0.05$.

\section{Results}

\section{Effect of the reproductive phase of initial injection}

The previous study (Hickford et al. 2001) found that the proportion of animals induced during the middle of the gestation phase was lower than those induced during the other reproductive phases. In this study, animals were not induced during the middle of the gestation phase, and with the exception of increased LF in non-cyclic animals (Table $1 ; P=0.003$ ), no significant difference was found in the number of $\mathrm{CL}$ and $\mathrm{GF}, \mathrm{AF}$, ovulated oocytes and conceptuses (Table 1) between the four reproductive phases. The time to ovulation after induction (Table 2) and the ovarian stimulation, mating, ovulation or fertilization success (Table 3 ) were also no different between the four reproductive phases. Therefore, the four reproductive phases have been pooled to evaluate the influence of the two hormone protocols and the three time of daily injection variables.

\section{Time to ovulation}

The time to ovulation after induction (Table 4; 7.8 \pm 0.9 days) was significantly shorter $(P=0.000)$ and less variable than in the previous study (Hickford et al. 2001) and significantly longer than naturally cycling animals (Table 4;P=0.033). There was no difference in the timing of ovulation after induction using eSG/eSG or $\mathrm{eSG} / \mathrm{LH}$, or the three time protocols (Table 4).

\section{Induction success}

A significantly lower proportion of animals induced using eSG/eSG in two evening injections (E/E) showed ovarian stimulation (Table $5 ; P=0.034$ ) compared to 
Table 1 Number of stimulatory products (per animal) found in Sminthopsis macroura that responded to the induced ovulation protocol during the four reproductive phases.

\begin{tabular}{|c|c|c|c|c|c|c|}
\hline \multirow[b]{2}{*}{$\begin{array}{l}\text { Reproductive } \\
\text { phase stimulated }\end{array}$} & \multirow[b]{2}{*}{$n$} & \multicolumn{5}{|c|}{ Stimulatory products (number per animal (mean \pm s.D.)) } \\
\hline & & $\begin{array}{c}\text { Corpora lutea or } \\
\text { Graafian follicles }(n)^{\mathrm{a}}\end{array}$ & $\begin{array}{l}\text { Luteinized } \\
\text { follicles }\end{array}$ & Atretic follicles & Ovulated oocytes $(n)^{\mathrm{b}}$ & Conceptuses $(n)^{\mathrm{c}}$ \\
\hline Non-cyclic & 7 & $29.0 \pm 16.6$ (5) & $15.3 \pm 21.0^{*}$ & $0.1 \pm 0.4$ & $26.5 \pm 7.8(2)$ & $0.0 \pm 0.0(2)$ \\
\hline Follicular & 17 & $35.5 \pm 14.3(13)$ & $3.7 \pm 8.1$ & $5.2 \pm 11.0$ & $15.5 \pm 11.9(10)$ & $0.0 \pm 0.0(3)$ \\
\hline Gestation & 11 & $39.6 \pm 18.5(11)$ & $2.4 \pm 6.6$ & $3.6 \pm 6.0$ & $23.9 \pm 12.8(8)$ & $2.4 \pm 3.2(5)$ \\
\hline Intermediate & 13 & $29.3 \pm 14.1(12)$ & $0.5 \pm 1.9$ & $4.3 \pm 6.1$ & $21.8 \pm 16.5(11)$ & $13.1 \pm 12.1$ (7) \\
\hline ANOVA & & $F_{3,38} 1.030$ & $F_{3,44} 4.006$ & $F_{3,44} 0.694$ & $F_{3,27} 0.750$ & $F_{3,13} 2.822$ \\
\hline$P$ value & & 0.391 & 0.003* & 0.561 & 0.532 & 0.080 \\
\hline
\end{tabular}

*Indicates significant difference from other reproductive phases. $P$ value level of significance is $<0.01$ (Bonferroni's adjustment). Sample size ( $n$ ) indicates the number of animals stimulated. Animals that were not induced were not included in this table.

${ }^{\mathrm{a}}$ Animals were excluded from analysis of the means if they were overstimulated. ${ }^{\mathrm{b}}$ Animals were excluded from analysis of the means if they did not ovulate. 'Animals were excluded from analysis of the means if they were not paired with a male or did not ovulate.

$\mathrm{M} / \mathrm{M}$ or $\mathrm{E} / \mathrm{M}$ protocols. However, the proportion of all induced animals that responded to the induction protocol (Table 5) was not significantly different from natural cycles.

The proportion of induced animals identified as having mated after being paired with a male (Table 5) was significantly higher than identified in natural cycles $(P=0.037)$, but in this study a successful mating was more likely to be identified during an induced cycle. Eight of nine induced animals (88.9\%) found with conceptuses were previously identified as having mated, but only two of nine (22.2\%) naturally cycling animals found with conceptuses were identified $\left(\chi^{2}\right.$ 5.625, $P=0.018$ ). The hormonal protocol and the time of injection did not influence the likelihood of an animal mating (Table 5).

The proportion of all induced animals that successfully ovulated (Table 5) was significantly lower than natural cycles $(P=0.042)$. No significant difference in the number of animals that ovulated was found between the two hormonal protocols, or the time of injection (Table 5).

The proportion of animals that had conceptuses (Table 5) was the same between induced and natural cycles. No animals induced using E/E injections were included in this analysis because all post-ovulation $\mathrm{E} / \mathrm{E}$ experiments occurred when oocytes were still in the oviduct. There was no significant difference in the number of animals with conceptuses between the two hormonal protocols, or the time of injection (Table 5).

\section{Induction products}

There were significantly more CL/GF (Table 6; $P=0.000$ ), ovulated oocytes (Table 6; $P=0.007$ ) and AF (Table 6; $P=0.009$ ) found in induced cycles than occurred in natural cycles. The number of conceptuses found after $\mathrm{E} / \mathrm{M}$ protocols was significantly higher in eSG/LH animals than in eSG/eSG animals (Table 6; $P=0.003$ ). No other differences in the products of induction were observed between the two hormonal protocols or the three time of injection protocols (Table 6).

\section{Induction of natural cycles}

One previously non-cyclic female gave birth to four pouch young in her first natural cycle following induced ovulation. The other four animals allowed to cycle naturally after induction showed normal follicular development and ovulation when examined during the first $(n=2)$ or second natural cycle $(n=2)$. The number of CA found was significantly higher in animals where the previous cycle was the induced cycle than those which were undergoing their second natural cycle $(1 \mathrm{st}$ $34.0 \pm 5.7, n=2 ; 2$ nd 15.5 $\pm 2.1, n=2 ; t=4.331$, df 2 , $P=0.049$ ), showing that although the number of $\mathrm{CL} / \mathrm{GF}$ was significantly higher in induced cycles, subsequent natural cycles return to normal levels. There was no difference in the number of products during oestrus or following ovulation in the induced natural cycles, and both the induced and natural cycles (Table 6), probably due to the low sample size. Two of five animals mated during the first natural cycle after induction, and one of these matings resulted in a litter. One of two animals mated during the second natural cycle, and this mating resulted in 17 fertilized conceptuses.

\section{Oviducal transit}

Animals found with oviducal oocytes exhibited oviducal peristalsis and the infundibulum completely enveloped

Table 2 The time to ovulation (days after first injection) in Sminthopsis macroura induced to ovulate during the four reproductive phases.

\begin{tabular}{lccc}
\hline & \multicolumn{3}{c}{ Time to ovulation (in days after 1st injection) } \\
\cline { 2 - 4 } $\begin{array}{l}\text { Reproductive } \\
\text { phase stimulated }\end{array}$ & $n$ & Mean \pm s.D. & Min, max \\
\hline Non-cyclic & 5 & $8.3 \pm 1.0$ & $7.0,9.0$ \\
Follicular & 13 & $7.8 \pm 0.9$ & $6.5,9.0$ \\
Gestation & 10 & $7.8 \pm 0.9$ & $7.0,9.5$ \\
Intermediate & 12 & $7.7 \pm 1.2$ & $5.0,9.0$ \\
ANOVA & & $F_{3,36} 0.488, P=0.693$ & \\
\hline
\end{tabular}

Animals that were not induced, or were overstimulated (as determined by follicle appearance) and therefore unable to ovulate, were not included in this table. 
Table 3 Comparison of the proportion of Sminthopsis macroura that showed ovarian stimulation, mated, ovulated and, if paired and ovulated, had conceptuses between the four reproductive phases of initial stimulation.

\begin{tabular}{lcccc}
\hline & \multicolumn{3}{c}{ Responders/total examined } \\
\cline { 2 - 5 } $\begin{array}{l}\text { Reproductive } \\
\text { phase stimulated }\end{array}$ & Induced $^{\mathrm{a}}$ & Mated $^{\mathrm{b}}$ & Ovulated $^{\mathrm{C}}$ & $\begin{array}{c}\text { With } \\
\text { conceptuses }^{\mathrm{d}}\end{array}$ \\
\hline Non-cyclic & $7 / 7$ & $2 / 7$ & $2 / 5$ & $0 / 2$ \\
Follicular & $17 / 18$ & $5 / 12$ & $11 / 16$ & $0 / 3$ \\
Gestation & $11 / 12$ & $4 / 7$ & $8 / 10$ & $3 / 6$ \\
Intermediate & $13 / 14$ & $6 / 10$ & $11 / 12$ & $6 / 8$ \\
$\chi^{2}$ & 0.611 & 2.057 & 5.420 & 0.143 \\
$P$ value & 0.894 & 0.561 & 0.143 & 0.073 \\
\hline
\end{tabular}

$\chi^{2}-$ chi-square analysis.

${ }^{\mathrm{a}} \mathrm{All}$ animals that received hormonal injections were included in this analysis of responders. ${ }^{b}$ Only animals that were induced and that were paired with a male were included in this analysis of responders. ${ }^{\mathrm{C}}$ Only animals that were induced and were examined from Day 7 were included in this analysis of responders. ${ }^{\mathrm{d}}$ Only animals that were induced, were paired with a male and ovulated were included in this analysis of responders.

the ovary. Maintenance of peristalsis for up to $18 \mathrm{~h}$ in vitro required the whole reproductive tract, especially with intact connective tissue from the oviduct to the ovary and uterus, to be held in HDMEM in the dark. Despite continual peristalsis in vitro, oocytes were generally static, moving down the oviduct in 'pulses' ( $n=6$ in 3 animals). During a 'pulse', a group (2.8 \pm 0.9 , $n=6$ ) of oocytes were quickly pushed along $1 / 4$ of the length of the oviduct in as little as $10 \mathrm{~min}(n=3)$. The first movement of oocytes occurred 30, 45, and 90 min after the beginning of culture. Unfortunately, no oocyte group moved more than once during the culture period, so we

Table 4 The time to ovulation in Sminthopsis macroura induced to ovulate with eSG/eSG or eSG/LH given in morning or evening injections.

\begin{tabular}{lrll}
\hline \multirow{2}{*}{$\begin{array}{l}\text { Hormone } \\
\text { (injection time) }\end{array}$} & \multicolumn{3}{c}{ Time to ovulation (in days after 1st injection) } \\
\cline { 2 - 4 } eSG/eSG & $n$ & Mean \pm s.D. & Min, max \\
M/M & 11 & $8.5 \pm 0.7$ & $7.0,9.0$ \\
E/M & 6 & $7.4 \pm 0.9$ & $6.5,9.0$ \\
E/E & 2 & $7.5 \pm 0.0$ & $7.5,7.5$ \\
eSG/LH & 14 & $7.6 \pm 1.1$ & $5.0,9.5$ \\
M/M & 5 & $7.6 \pm 0.8$ & $7.0,9.0$ \\
E/M & 2 & $8.0 \pm 0.7$ & $7.5,8.0$ \\
E/E & & $F_{6,37} 2.054$ & $P=0.083$ \\
Two-way ANOVA & 40 & $7.8 \pm 0.9^{*}$ & $5.0,9.5$ \\
Total induced & 22 & $9.4 \pm 3.9$ & $3.0,16.0$ \\
Hickford et al. (2001) & & $t=10.188$ & $P=0.000^{*}$ \\
Total vs Hickford et al. & & $7.0 \pm 1.1$ & $5.0,9.0$ \\
Natural & 8 & $t=2.194$ & $P=0.033^{+}$ \\
Total vs natural & & &
\end{tabular}

Animals that were not induced, or were overstimulated (as determined by follicle appearance) and therefore unable to ovulate, were not included in this table. *Indicates significant difference from Hickford et al. (2001). ${ }^{\dagger}$ Indicates significant difference from natural cycles. $\mathrm{eSG}$, equine serum gonadotrophin; $\mathrm{LH}$, luteinizing hormone; $\mathrm{M} / \mathrm{M}$, morning/morning injections; E/M, evening/morning injections; $E / E$, evening/evening injections.
Table 5 Comparison of the proportion of Sminthopsis macroura that showed ovarian stimulation, mated, ovulated and had conceptuses after induced ovulation with eSG/eSG or eSG/LH given in morning or evening injections.

\begin{tabular}{|c|c|c|c|c|}
\hline \multirow{2}{*}{$\begin{array}{l}\text { Induction } \\
\text { hormone } \\
\text { (injection } \\
\text { time) }\end{array}$} & \multicolumn{4}{|c|}{ Responders/total examined } \\
\hline & Induced $^{\mathrm{a}}$ & Mated $^{b}$ & Ovulated $^{\mathrm{C}}$ & With conceptuses ${ }^{\mathrm{d}}$ \\
\hline \multicolumn{5}{|l|}{ eSG/eSG } \\
\hline $\mathrm{M} / \mathrm{M}$ & $14 / 14$ & $4 / 11$ & $8 / 12$ & $4 / 6$ \\
\hline $\mathrm{E} / \mathrm{M}$ & $6 / 6$ & $2 / 6$ & $5 / 6$ & $1 / 5$ \\
\hline $\mathrm{E} / \mathrm{E}$ & $3 / 5^{*}$ & $3 / 3$ & $2 / 3$ & na \\
\hline$\chi^{2}$ & 8.696 & 4.328 & 0.328 & 1.742 \\
\hline $\begin{array}{l}\tilde{P}_{\text {value }} \\
e S G / L H\end{array}$ & $0.034^{*}$ & 0.115 & 0.849 & 0.187 \\
\hline $\mathrm{M} / \mathrm{M}$ & $15 / 16$ & $4 / 9$ & $11 / 13$ & $4 / 9$ \\
\hline $\mathrm{E} / \mathrm{M}$ & $5 / 5$ & $1 / 2$ & $4 / 5$ & $2 / 2$ \\
\hline $\mathrm{E} / \mathrm{E}$ & $5 / 5$ & $3 / 5$ & $1 / 4$ & na \\
\hline$\chi^{2}$ & 0.650 & 0.311 & 5.653 & 2.037 \\
\hline$\stackrel{\imath}{P}$ value & 0.723 & 0.856 & 0.059 & 0.154 \\
\hline \multicolumn{5}{|c|}{ eSG/eSG vs eSG/LH } \\
\hline$M / M \chi^{2}$ & $\begin{array}{c}0.905 \\
P=0.341\end{array}$ & $\begin{array}{c}0.135 \\
P=0.714\end{array}$ & $\begin{array}{c}0.361 \\
P=0.548\end{array}$ & $0.444, P=0.505$ \\
\hline $\mathrm{E} / \mathrm{M} \chi^{2}$ & $\begin{array}{c}0.000 \\
P=1.000\end{array}$ & $\begin{array}{c}0.178 \\
P=0.673\end{array}$ & $\begin{array}{c}0.020 \\
P=0.887\end{array}$ & $3.733, P=0.053$ \\
\hline $\mathrm{E} / \mathrm{E} \chi^{2}$ & $\begin{array}{c}2.500 \\
P=0.114\end{array}$ & $\begin{array}{c}1.600 \\
P=0.206\end{array}$ & $\begin{array}{c}1.215 \\
P=0.270\end{array}$ & na \\
\hline $\begin{array}{l}\text { Total } \\
\text { induced }\end{array}$ & $48 / 51$ & $17 / 36^{+}$ & $31 / 43^{+}$ & $11 / 19$ \\
\hline Natural & $32 / 32$ & $2 / 16$ & $26 / 27$ & $9 / 15$ \\
\hline$\chi^{2}$ & 1.953 & 5.759 & 5.589 & 0.537 \\
\hline$\stackrel{\lambda}{P}$ value & 0.162 & $0.037^{+}$ & $0.042^{+}$ & 0.464 \\
\hline
\end{tabular}

*Indicates significant difference from other injection times using the same hormone protocol by $\chi^{2}$ (chi-square) analysis. ${ }^{\dagger}$ Indicates significant difference from natural cycles using $\chi^{2}$ analysis.

${ }^{a}$ All animals that received injections were included in the analysis of responders. ${ }^{b}$ Only animals that were induced and that were paired with a male were included in this analysis of responders. ${ }^{\circ}$ Only animals that were induced and were examined from Day 7 were included in this analysis of responders. ${ }^{\mathrm{d}}$ Only animals that were induced, were paired with a male and ovulated were included in this analysis of responders. eSG, equine serum gonadotrophin; LH, luteinizing hormone; $M / M$, morning/morning injections; $E / M$, evening/morning injections; $E / E$, evening/evening injections; na, not available.

estimate that a $1 \mathrm{~h}$ long period of stasis between oocyte movements is likely, given the range of times for first movement after culture initiation. Ovulation was observed four times (from three animals) in vitro, and occurred at 30, $45 \mathrm{~min}, 4$ and $5 \mathrm{~h}$ after the beginning of culture. The appearance of oocytes in the upper ampulla after ovulation took $<10 \mathrm{~min}$ in one event, and $<30 \mathrm{~min}$ in all observed events. One animal ovulated twice in culture, and the second ovulation occurred within $1 \mathrm{~h}$ of the first. The discrete placement of oocyte groups found spaced along the oviduct and in the uterus of two animals and the separate ovulation events observed during culture, indicate that more than one ovulation 'event' occurred for most animals. The maximum number of ovulation events suggested by oocyte placement and observed ovulations was four, but the average was $1.8( \pm 1.3, n=5)$. Ovulation was not synchronous between the ovaries, with three of five 
Table 6 The number of corpora lutea or Graafian follicles, luteinized follicles, atretic follicles, ovulated oocytes and conceptuses, found in Sminthopsis macroura induced to ovulate using eSG/eSG or eSG/LH given in morning or evening injections.

\begin{tabular}{|c|c|c|c|c|c|}
\hline \multirow[b]{2}{*}{$\begin{array}{l}\text { Induction hormone } \\
\text { (injection time) }\end{array}$} & \multicolumn{5}{|c|}{ Number per animal (mean \pm S.D.) } \\
\hline & $\begin{array}{l}\text { Corpora lutea or } \\
\text { Graafian follicles }(n)^{\text {a }}\end{array}$ & Luteinized follicles $(n)$ & Atretic follicles $(n)$ & Ovulated oocytes $(n)^{\mathrm{b}}$ & Conceptuses $(n)^{\mathrm{c}}$ \\
\hline \multicolumn{6}{|l|}{ eSG/eSG } \\
\hline $\mathrm{M} / \mathrm{M}$ & $25.6 \pm 13.3(13)$ & $1.4 \pm 3.7(14)$ & $2.4 \pm 5.5(14)$ & $20.6 \pm 15.7(7)$ & $13.7 \pm 18.0(3)$ \\
\hline $\mathrm{E} / \mathrm{M}$ & $40.0 \pm 14.7(5)$ & $4.7 \pm 11.4(5)$ & $1.8 \pm 2.5(5)$ & $19.6 \pm 7.5(5)$ & $0.4 \pm 0.9(5)^{*}$ \\
\hline$E / E$ & $41.6 \pm 11.0(3)$ & $17.7 \pm 30.6(3)$ & $0.0 \pm 0.0(3)$ & $20.5 \pm 3.5(2)$ & na \\
\hline ANOVA & $F_{2,18} 3.131$ & $F_{2,20} 2.432$ & $F_{2,19} 0.339$ & $F_{2,12} 0.040$ & $F_{1,6} 3.056$ \\
\hline$P$ value & 0.068 & 0.113 & 0.716 & 0.961 & 0.131 \\
\hline \multicolumn{6}{|l|}{$e S G / L H$} \\
\hline $\mathrm{M} / \mathrm{M}$ & $35.1 \pm 17.9(15)$ & $1.9 \pm 5.8(15)$ & $5.3 \pm 9.2(15)$ & $22.9 \pm 17.0(11)$ & $5.3 \pm 8.5(7)$ \\
\hline E/M & $32.6 \pm 11.5(5)$ & $0.8 \pm 1.9(5)$ & $6.2 \pm 7.8(5)$ & $24.3 \pm 9.6(4)$ & $12.0 \pm 5.7(2)^{*}$ \\
\hline E/E & $61.0 \pm .(1)$ & $11.0 \pm 15.1$ & $6.4 \pm 14.3(5)$ & $7.0 \pm .(1)$ & na \\
\hline ANOVA & $F_{2,18} 1.243$ & $F_{2,22} 2.782$ & $F_{2,22} 0.032$ & $F_{2,13} 0.521$ & $F_{1,7} 1.046$ \\
\hline$P$ value & 0.312 & 0.084 & 0.969 & 0.606 & 0.341 \\
\hline \multicolumn{6}{|l|}{ eSG/eSG vs eSG/LH } \\
\hline $\mathrm{M} / \mathrm{M}$ t-test & $t 1.577$ & $t 0.256$ & $t 0.956$ & $t 0.342$ & $t 1.044$ \\
\hline$P$ value & 0.268 & 0.800 & 0.347 & 0.735 & 0.327 \\
\hline $\mathrm{E} / \mathrm{M} t$-test & $t 0.885$ & $t 0.7429$ & $t 1.203$ & $t 0.029$ & $t 5.225$ \\
\hline$P$ value & 0.402 & 0.477 & 0.263 & 0.978 & $0.003^{*}$ \\
\hline $\mathrm{E} / \mathrm{E} t$-test & $t 1.520$ & $t 0.424$ & $t 0.750$ & $t 1.607$ & na \\
\hline$P$ value & 0.268 & 0.751 & 0.482 & 0.152 & \\
\hline Total induced & $33.5 \pm 15.8(42)^{\dagger}$ & $3.9 \pm 10.4(48)$ & $3.9 \pm 7.9(48)^{\dagger}$ & $22.8 \pm 12.5(28)^{\dagger}$ & $6.1 \pm 9.8(17)$ \\
\hline Natural & $20.0 \pm 8.72(26)$ & $0.7 \pm 3.7(24)$ & $0.6 \pm 2.3(24)$ & $14.6 \pm 8.7(26)$ & $7.5 \pm 10.0(14)$ \\
\hline$t$-Test & 3.999 & 1.881 & 2.710 & 2.784 & 0.388 \\
\hline$P$ value & $0.000^{\dagger}$ & 0.065 & $0.009^{\dagger}$ & $0.007^{\dagger}$ & 0.701 \\
\hline $\begin{array}{l}\text { Induced natural cycle } \\
\text { vs Induced }\end{array}$ & $18.0 \pm 1.4(4)$ & $0.0 \pm 0.0$ & $1.3 \pm 1.9(4)$ & $16.5 \pm 0.7(2)$ & $8.5 \pm 12.0(2)$ \\
\hline$t$-test & 0.735 & 0.672 & 1.945 & 0.186 & 0.694 \\
\hline$P$ value & 0.466 & 0.505 & 0.058 & 0.853 & 0.552 \\
\hline \multicolumn{6}{|l|}{ vs Natural } \\
\hline$t$-test & 0.402 & 0.555 & 0.451 & 0.613 & 0.610 \\
\hline$P$ value & 0.691 & 0.584 & 0.656 & 0.544 & 0.548 \\
\hline
\end{tabular}

*Indicates significant difference between the two hormonal protocols in E/M animals. ${ }^{\dagger}$ Indicates significant difference from natural cycles. $P$ value level of significance is $<0.01$ (Bonferroni's adjustment). Sample size $(n)$ indicates the number of animals stimulated. Animals that were not induced were not included in this table.

${ }^{\mathrm{a}}$ Animals were excluded from analysis of the means if they were overstimulated. ${ }^{\mathrm{b}}$ Animals were excluded from analysis of the means if they did not ovulate. ${ }^{\mathrm{C}}$ Animals were excluded from analysis of the means if they were not paired with a male or did not ovulate.

eSG, equine serum gonadotrophin; LH, luteinizing hormone; $M / M$, morning/morning injections; $E / M$, evening/morning injections; E/E,

evening/evening injections; na, not available.

animals showing asynchronous ovulations based on initial oocyte position in the oviduct and uterus at the beginning of the culture.

\section{Discussion}

Non-cyclic animals that were induced to ovulate began cycling naturally, showing follicular development, mating, ovulation and fertilization. The birth of a litter from a natural cycle following induced ovulation makes this protocol promising for the captive breeding of dasyurids with asynchronous breeding. Non-cyclic females can be induced to ovulate and then to cycle naturally, allowing pairing with breeding males.

The timing of induced ovulation was highly predictable using this protocol. Both induced and natural ovulations occurred before 07:00 h, with oocytes found in the oviduct in the early morning. This photoperiod constraint on the timing of ovulation is reflected in our
S.D. ( \pm 1.0 days). The day of ovulation in mammals is regulated by increasing ovarian oestradiol secretion (Johnson \& Everitt 2000) and the time of day of ovulation is regulated by a stimulus from the suprachiasmatic nuclei in the hypothalamus, which induces the LH surge from the anterior pituitary (Kawakami et al. 1980, Gajewska et al. 2005). Interestingly, in this study, there was no difference in the time of ovulation after morning or evening LH stimulation. Our results suggest that there is a third tier of control, which prevents ovulation if the LH surge occurs at the wrong time of day. Recent studies have identified a circadian rhythm in the expression of two clock genes, per 1 and per2, in steroidogenic cells of the rat ovary (Fahrenkrug et al. 2006), which may regulate intraovarian processes leading to ovulation.

The size and degree that the infundibulum envelopes the ovary indicates the closeness to the time of ovulation in vivo (Woolley 1990). In this in vitro study, one infundibulum was observed to retreat slightly within $1 \mathrm{~h}$ 
of the last in vitro ovulation, supporting our conclusion that oviducal oocytes were recently ovulated. This study is the first in vitro investigation into the time taken by oocytes to travel through the marsupial oviduct. In vitro oocyte movement occurred in pulses, which is also observed in rabbits (Bourdage \& Halbert 1984). However, if oocyte movement is continuous in vivo, our results suggest that it could take as little as $40 \mathrm{~min}$ for one group of oocytes to travel the length of the oviduct, from the upper ampulla to uterine entry. If the stasis observed is natural, we suggest that a 1 -h period of stasis occurs after each movement. Thus, one group of oocytes would take about $4 \mathrm{~h}$ to move through the oviduct. Staggered ovulation events occurred in vivo and in vitro, both in time, with discrete groups of oocytes found spaced through the oviducts and between ovaries. In vitro, two ovulation events from the same ovary occurred only in one animal, 1-h apart and oocytes moved into the upper ampulla within as little as $10 \mathrm{~min}$. In polyovular $S$. macroura, multiple ovulation events occur naturally (Selwood \& Woolley 1991), explaining the short time between ovulation events found in this study compared to the monovular Trichosurus vulpecula (Glazier 1999) which had 2 ovulations over $6 \mathrm{~h}$ in vivo and M. eugenii (Molinia et al. 1998), which had 9 ovulations over $9 \mathrm{~h}$ in vivo. A maximum of four ovulation events in the one animal occurred in this study. In mice (Braden 1957) and pigs (Pope et al. 1988) all ovulations occurred within $3 \mathrm{~h}$, however, it is unclear if they occur singly or in groups. We estimate that the total ovulation time (including four ovulation events) in $S$. macroura could take as little as $4 \mathrm{~h}$ if stasis does not occur in vivo, or $7.5 \mathrm{~h}$ if the oocytes remain static for $1 \mathrm{~h}$ in each region of the oviduct. Selwood \& Woolley (1991) estimated total oviducal transit time in $S$. macroura was between 7 and $12 \mathrm{~h}$ and our findings suggest that it could be less than that. The transit of oviducal oocytes in pulses was seen here and in rabbits (Bourdage \& Halbert 1984), both species with significant contributions to egg investments made by the oviduct. Secretion by the oviducal epithelium is enhanced by the presence of an oocyte in M. domestica (Phillips \& Fadem 1987), suggesting that pauses in oviducal transit may allow synthesis of secretory proteins by the oviducal epithelium prior to further transit. The rapid oviducal transit of marsupial oocytes compared to eutherian oocytes is possibly because the marsupial conceptus must be surrounded by a shell coat, which is secreted by the uterine glandular epithelium, before blastocyst formation (Moore \& Taggart 1993, Renfree \& Lewis 1996, Casey \& Selwood 2003) to prevent dispersal of the blastocyst epithelium (Casey \& Selwood 2003) after mucoid coat loss.

The previous induced ovulation study in S. macroura (Hickford et al. 2001) followed the protocol used in S. crassicaudata (Rodger et al. 1992), with equivalent results. Other induced ovulation studies in marsupials have used similar hormones, concentrations and timing of injections, with broadly similar results in a diverse range of species (Hinds et al. 1996, Glazier \& Molinia 1998, Molinia et al. 1998, Glazier 1999). Following these data, we suggest that our protocol, where the second hormone injection is given at the beginning of oestrus, when oocytes are beginning to mature, will successfully induce predictable ovulation and natural cycling in other dasyurid species. However, we believe a return to the use of body weight to calculate an appropriate hormone dosage would reduce the number of LF and AF found on the ovary, especially in non-cyclic animals.

Whilst captive breeding of dasyurid species has been well documented (Godfrey 1969, Woolley 1966, 1971), it is labour intensive. An induced ovulation protocol such as this one, allows breeding from older and noncyclic females, as well as making the time of mating and ovulation more predictable, which is useful in populations with limited males or where the remaining animals show asynchronous breeding.

\section{Acknowledgements}

The authors wish to thank all members of the Selwood Laboratory between 2000 and 2005, particularly Kamani Nanayakkara and Angela Nation. We also wish to thank Steve Swearer for his statistical advice. This research was supported by the Australian Research Council. The authors declare that there is no conflict of interest that would prejudice the impartiality of this scientific work.

\section{References}

Austin CR \& Braden AWH 1954 Time relation and their significance in the ovulation and penetration of eggs in rats and rabbits. Australian Journal of Biological Sciences 7 179-194.

Bourdage RJ \& Halbert SA 1984 Quantification of intraluminal motion of surrogate ova in the rabbit oviducatal isthmus. Biology of Reproduction 30 1124-1129.

Braden AWH 1957 The relationship between the diurnal light cycle and the time of ovulation in mice. Journal of Experimental Biology 34 177-188.

Breed WG \& Leigh CM 1992 Marsupial fertilization: some further ultrastructural observations on the dasyurid Sminthopsis crassicaudata. Molecular Reproduction and Development 32 277-292.

Casey NP \& Selwood L 2003 Removal of the shell coat affects maintenance of epithelia in blastocysts of the brushtail possum in vitro. Cells, Tissues, Organs 173 21-45.

Fahrenkrug J, Georg B, Hannibal J, Hindersson P \& Gräs S 2006 Diurnal rhythmicity of the clock genes Per1 and Per2 in the rat ovary. Endocrinology 147 3769-3776.

Gajewska A, Wolinska-Witort E \& Kochman K 2005 Vasoactive intestinal peptide modulates luteinizing hormone subunit gene expression in the anterior pituitary in female rat. Brain Research Bulletin 67 319-326.

Glazier AM 1999 Time of ovulation in the Brushtail Possum (Trichosurus vulpecula) following PMSG/LH induced ovulation. Journal of Experimental Zoology 283 608-611. 
Glazier AM \& Molinia FC 1998 Improved method of superovulation in monovulatory brushtail possums (Trichosurus vulpecula) using pregnant mares' serum gonadotrophin-luteinizing hormone. Journal of Reproduction and Fertility 113 191-195.

Godfrey GK 1969 Reproduction in a laboratory colony of the marsupial mouse Sminthopsis larapinta (Marsupialia: Dasyuridae). Australian Journal of Zoology 17 637-654.

Harper MJK 1988 Gamete and zygote transport. In The Physiology of Reproduction, pp 103-134. Eds E Knobil, J Neill, LL Ewing, GS Greenwald, CL Market \& DW Pfaff. New York: Raven Press.

Hickford DE, Merry NE, Johnson MH \& Selwood L 2001 Induced ovulation, mating success and embryonic development in the stripefaced dunnart, Sminthopsis macroura. Reproduction 122 777-783.

Hinds LA, Fletcher TP \& Rodger JC 1996 Hormones of oestrus and ovulation and their manipulation in marsupials. Reproduction, Fertility, and Development 8 661-672.

Johnson MH \& Everitt BM 2000 Essential Reproduction, Oxford: Blackwell Science.

Kawakami M, Arita J \& Yoshioka E 1980 Loss of oestrogen-induced daily surges of prolactin and gonadotrophins by suprachiasmatic nucleus lesions in ovariectomized rats. Endocrinology 106 1087-1092.

Menkhorst P \& Knight F 2004 A Field Guide to the Mammals of Australia, Melbourne: Oxford University Press.

Molinia FC, Gibson RJ, Smedley MA \& Rodger JC 1998 Further observations of the ovarian response of the tammar wallaby (Macropus eugenii) to exogenous gonadotrophins: an improved method for superovulation using FSH/LH. Animal Reproduction Science 53 253-263.

Moore HDM \& Taggart DA 1993 In vitro fertilization and embryo culture in the grey short-tailed opossum Monodelphis domestica. Journal of Reproduction and Fertility 98 267-274.

Pederson ES 1951 Histogenesis of lutein tissue of the albino rat. American Journal of Anatomy 88 397-427.

Phillips DM \& Fadem BH 1987 The oocyte of a new world marsupial, Monodelphis domestica: structure, formation, and function of the enveloping mucoid layer. Journal of Experimental Zoology 242 363-371.
Pope WF, Wilde MH \& Xie S 1988 Effect of electrocautery of nonovulated Day 1 follicles on subsequent morphological variation among Day 11 porcine embryos. Biology of Reproduction 39 882-889.

Renfree MB \& Lewis AM 1996 Cleavage in vivo and in vitro in the marsupial Macropus eugenii. Reproduction, Fertility, and Development 8 725-742.

Rodger JC, Breed WG \& Bennett JH 1992 Gonadotrophin-induced oestrus and ovulation in the polyovulatory marsupial Sminthopsis crassicaudata. Reproduction, Fertility, and Development 4 145-152.

Runner M 1947 Attempts at in vitro semination of mouse egg. Anatomical Record 99 564-565.

Selwood L \& Hickford DE 1999 Early cell lineages in marsupial embryos. In Cell Lineage and Fate Determination, pp 505-519. Ed. S Moody. Burlington: Academic Press.

Selwood L \& McCallum F 1987 Relationship between longevity of spermatozoa after insemination and the percentage of normal embryos in brown marsupial mice (Antechinus stuartii). Journal of Reproduction and Fertility 79 495-503.

Selwood L \& Woolley PA 1991 A timetable of embryonic development, and ovarian and uterine changes during pregnancy, in the stripefaced dunnart, Sminthopsis macroura (Marsupialia: Dasyuridae). Journal of Reproduction and Fertility 91 213-227.

Tyndale-Biscoe CH \& Renfree MB 1987 Reproductive Physiology of Marsupials, Cambridge: Cambridge University Press.

Woolley PA 1966 Reproduction in Antechinus spp. and other dasyurid marsupials. Symposium of the Zoological Society London $\mathbf{1 5}$ 281-294.

Woolley PA 1971 Maintenance and breeding of laboratory colonies of Dasyuroides byrnei and Dasycercus cristicauda. International Zoology Yearbook II 54 351-354.

Woolley PA 1990 Reproduction in Sminthopsis macroura (Marsupialia: Dasyurida) 1. The Female. Australian Journal of Zoology 38 187-205.

Received 6 October 2006

First decision 27 November 2006

Accepted 21 December 2006 